\title{
Meiobenthic community underneath the carcass of a stingray: a snapshot after natural death
}

\author{
Gustavo Fonseca $^{1,2, *}$, Pat Hutchings ${ }^{2}$, Danilo Candido Vieira ${ }^{1}$, Fabiane Gallucci ${ }^{1,2}$ \\ ${ }^{1}$ Centro de Biologia Marinha da Universidade de São Paulo, Rodovia Manoel Hypólito do Rego, km 131.5, \\ São Sebastião 11600-000, Brazil \\ ${ }^{2}$ Australian Museum, 6 College Street, Sydney 2010, New South Wales, Australia
}

\begin{abstract}
The impact of large food falls and carrion on meiobenthic communities remains little understood. The objective of the present study was to investigate whether the carcass of a stingray, encountered fortuitously in an Australian estuary, affects the underlying meiobenthic community, in particular nematode assemblages. The integrity of the skeleton and the low redox values observed under the carcass suggest that the cadaver had been slowly and chiefly decomposed by microbes. The abundance and number of meiofaunal taxa, as well as nematode abundance and nematodespecies richness, were significantly lower under the carcass when compared to samples outside the carcass. Nonetheless, a few nematode species, typical of hypoxic/anoxic sediments, were more abundant under the carcass. Interestingly, all these species were absent or rare in samples near, but not under, the carcass, suggesting that they may take advantage of the reduced environment created by the carcass and the consequent lack of competition to prosper. As observed for other marine environments, carcasses in estuaries create a microhabitat that supports a characteristic meiobenthic fauna, distinct from those inhabiting the surrounding sediments, but similar to those of reduced habitats.
\end{abstract}

KEY WORDS: Meiofauna $\cdot$ Food fall $\cdot$ Nematode communities $\cdot$ Estuary $\cdot$ Australia

\section{INTRODUCTION}

Nekton carcasses from fishes, birds, cetaceans and other large animals have pronounced effects on benthic organisms from a variety of aquatic environments (Ramsay et al. 1997). Once deposited on the bottom, carcasses attract several opportunist species and are usually consumed within a few days. In the deep sea, for instance, the carcasses of whales attract dense aggregations of mobile scavengers, including dramatically increased numbers of macrofaunal species, several being unique to the carcasses (Smith et al. 2002, Smith \& Baco 2003, Dahlgren et al. 2004, Glover et al. 2005, Fujikura et al. 2006). In the North Sea, the fish discards produced by the beam-trawl fishery attract several species of invertebrate scavengers, such as brittle stars, starfish, gadoids, and hermit and swimming crabs (Kaiser \& Spencer 1994, Groenewold \& Fonds 2000). In the same way, the upstream migration and subsequent death of salmons and other cyprinids attracts the larvae of different insects (Chaloner et al. 2002). Although the importance of carcass decomposition as a transfer mechanism for nutrients and energy across trophic levels and ecosystem boundaries has been widely recognized (King et al. 2007), benthic studies focusing on its ecological importance have predominantly investigated the effect of carcasses on macroorganisms. To date there are few data available on the impact of carcasses on smaller meiobenthic organisms (organisms retained by $0.32 \mu \mathrm{m}$ mesh and passing through $0.5 \mathrm{~mm}$ mesh; Giere 2009), the numerically dominant metazoans representative of the benthos of most marine and brackish water habitats (Heip et al. 1985).

Studies on the meiofauna associated with carrion showed varying results. In the deep sea, the abundance of the dominant group of meiofauna, the nematodes, was negatively affected by whale carcasses 
(Debenham et al. 2004, Pavlyuk et al. 2009). Shallowwater studies, on the other hand, did not observe significant differences in nematode abundances between samples with and without carrion (Gerlach 1977, Ólafsson 1992, Franco et al. 2008). A common finding among these studies is that carrion significantly affected nematode composition, favoring a few genera but not others (Gerlach 1977, Ólafsson 1992, Franco et al. 2008, Pavlyuk et al. 2009). In addition to these studies, there is evidence from the North Sea that the freeliving marine nematode Pontonema vulgare is attracted to dead and moribund organisms (Lorenzen et al. 1987, Prein 1988). Given such paucity of data, the effect of carrion on meiobenthic organisms remains little understood.

The objective of the present study was to investigate how the carcass of a stingray, encountered fortuitously in an Australian estuary, affected the meiobenthic community, in particular nematode assemblages. Specifically, the study examined the hypothesis that no differences occur in meiofaunal and nematode abundances, number of taxa, or faunal composition between samples taken underneath this carcass and those taken nearby. Additionally, the present study aimed at investigating whether there is a specialized nematode scavenger assemblage or whether opportunistic/generalist species take advantage of the new environment created by the carcass.

\section{MATERIALS AND METHODS}

Study area and the carcass. The carcass of a stingray was found in December 2009 at $0.5 \mathrm{~m}$ water depth in Basin View, St. Georges Basin, in the southeast of New South Wales, Australia ( $35^{\circ} 5^{\prime} 43^{\prime \prime}$ S, $150^{\circ} 33^{\prime} 29^{\prime \prime}$ E). The basin covers an area of approximately $42 \mathrm{~km}^{2}$ and has a catchment area of $348 \mathrm{~km}^{2}$. St. Georges Basin is relatively shallow (0 to $10 \mathrm{~m}$ water depth), mesotrophic to eutrophic, and incorporates a wide variety of sedimentary habitats: sand banks, saltmarshes, seagrasses, rocky reefs, mangroves, intertidal flats, fluvial delta and a channel (Murray et al. 2005). Like other Australian estuaries, St Georges Basin receives little input of freshwater and is highly saline throughout the year (35 psu at the sampling site) (Hutchings 1999). The basin is permanently open to the ocean, with little water exchange due to the long and narrow outlet. The benthic environment at the basin is variable; overall, diatoms are the primary source of organic matter, and the organic matter in the sediment is mainly degraded by anaerobiosis (Murray et al. 2005).

The carcass was found lying on bare sediment and was partially degraded (Fig. 1). The skeleton was intact, and the flesh was partially decomposed, mainly on the wings and tail. The nose was partially covered with sediment and intact. The cadaver formed a black halo in the sediment, indicating the lack of oxygen and presence of sulfides. The skeleton of the carcass measured approximately $60 \mathrm{~cm}$ in width. The dead animal probably belonged to the species Dasyatis brevicauda Hutton, 1875 or D. thetidis Ogilby, 1899 (M. McGrouther pers. comm., Australian Museum). Both are widespread, temperate, Southern Hemisphere species recorded in Australia, New Zealand and southern Africa, occurring in a wide variety of habitats including shallow coastal bays, estuaries, lagoons, large inlets, coastal rocky reefs, offshore islands and open sea floor (Duffy \& Paul 2003, Stevens 2008). Although very little is known about their populations, during summer, $D$. brevicauda forms large aggregates for mating (Duffy \& Paul 2003). Recreational fishers and bycatch from inshore trawling are probably the main causes of their decline and the production of cadavers (Stevens 2008).

Sampling and sample processing. Four samples (core of $2 \mathrm{~cm}$ inner diameter and $3 \mathrm{~cm}$ in depth) of meiofauna were taken from underneath the stingray, and 4 samples were taken from adjacent sediments outside the carcass. No samples were taken inside or on the carcass. The samples 'outside' the carcass were randomly taken up to $1 \mathrm{~m}$ from the cadaver. Another 3 samples of the same size were taken under and outside

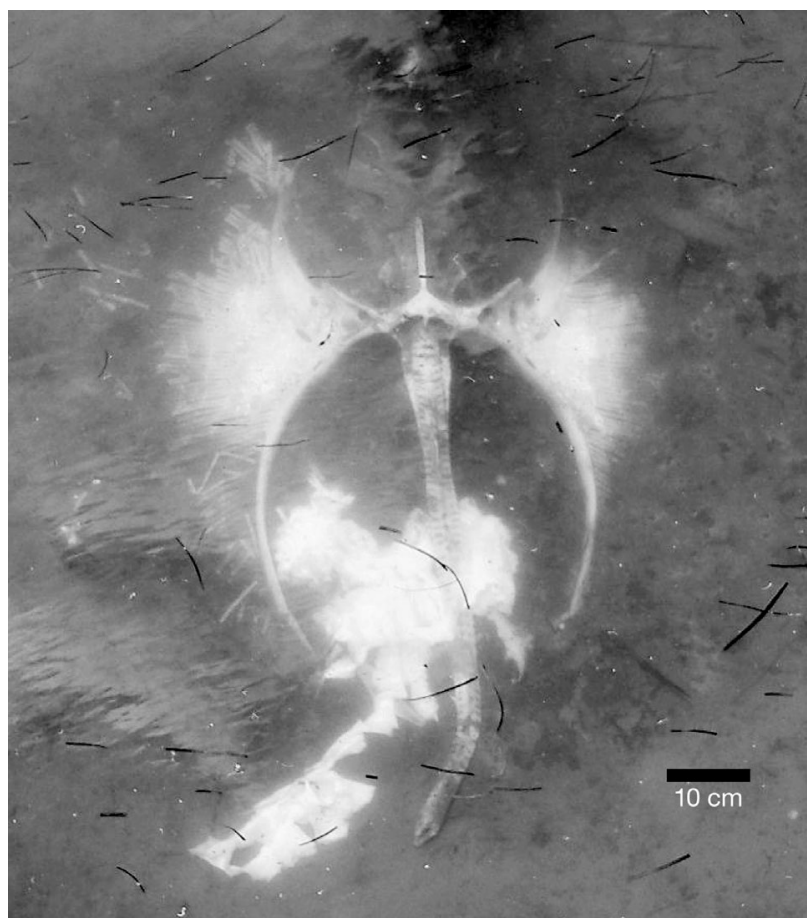

Fig. 1. Carcass of a stingray measuring ca. $60 \mathrm{~cm}$ in width found at a water depth of $0.5 \mathrm{~m}$ in St. Georges Basin, NSW, Australia. Black strips on the water surface are leaves of Zoostera capricorni from adjacent areas 
the carcass to determine total organic matter and redox potentials. Redox potentials were analyzed in the surface layer.

Samples for the investigation of meiofauna were fixed in $10 \%$ formalin immediately after sampling. In the laboratory, samples were washed through a $45 \mu \mathrm{m}$ sieve, extracted by flotation with a solution of colloidal silica (LUDOX TM-50; density: $1.18 \mathrm{~g} \mathrm{~cm}^{-3}$ ), stained with Rose Bengal and sorted under a low-power stereo microscope (Heip et al. 1985). All nematodes from samples under the carcass were picked out, transferred to anhydrous glycerol and mounted on permanent slides for identification. From samples outside the carcass, $10 \%$ of all nematodes were randomly picked out and mounted on permanent slides for identification. Nematodes were identified under the microscope to genus level (Warwick et al. 1998) and were separated into putative morphospecies, while the other groups were identified to a higher taxonomic level (phylum or class). All material has been deposited in the Australian Museum.

Sediment total organic matter (OM) was estimated by dry weight after combustion at $550^{\circ} \mathrm{C}$ for $4 \mathrm{~h}$. Redox potential was measured at the sediment surface using a Metrohm AG 9109 Herisau Combined Pt-wire electrode, with an $\mathrm{Ag} / \mathrm{AgCl}$ reference electrode. The instrument was calibrated using Orion Application Solution ORP Standard 967961, and all redox readings were corrected for EHRef $=-210 \pm 3 \mathrm{mV}$, i.e. reported redox potentials are versus that of the hydrogen electrode, $\mathrm{EHO}=0 \mathrm{mV}$.

Data analysis. As univariate descriptors of the fauna, abundance, number of higher meiofaunal taxa and number of nematode species were considered. ANOVA was applied to test for differences in all univariate measures between under the carcass and outside the carcass. Differences in the multivariate structure of meiofaunal communities and nematode assemblages were analyzed by means of analysis of similarity (ANOSIM; Clarke \& Gorley 2006). Multivariate analyses were conducted on Euclidean-distance similarity matrices. For the meiofauna, presence/absence data were used to remove the relative importance of nematodes. For nematodes, data were standardized to eliminate the effect of density, and no transformation was applied. To visualize the multivariate structure of the meiofaunal and nematode assemblages, non-metric multidimensional scaling ordination (nMDS) was performed based on the same Euclidian-distance similarity matrix. To identify which nematode species were the most important in characterizing differences between samples from under and outside the carcass, a similartiy percentage (SIMPER) analysis was conducted. All multivariate analyses were performed with PRIMER v6.0 (Clarke \& Gorley 2006).

\section{RESULTS AND DISCUSSION}

The integrity of the skeleton, the presence of remaining flesh and the apparent absence of macroinvertebrates on the carcass (Fig. 1) suggest that the cadaver had been slowly and chiefly decomposed by microbes. Although no macrofaunal or microbial samples were taken, the low redox values observed in surface sediments underneath the carcass in comparison to the samples from outside the carcass (Fig. 2) provide additional evidence for strong microbial degradation of the stingray cadaver, as this was probably a result of higher oxygen consumption due to microbial decomposition of the carrion (Tang et al. 2006). Larger scavengers, like starfish, fish and amphipods can consume large amounts of food falls in $<5 \mathrm{~d}$ (Kaiser \& Moore 1999). However, microbial decomposition is much slower, taking several weeks to months, depending on the local conditions, to completely decompose a fish carcass (Minshall et al. 1991, Parmenter \& Lamarra 1991, Fenoglio et al. 2005, Premke et al. 2010). This much slower decomposition is partly due to the fact that scavenger microbes produce noxious chemicals that deter animal scavengers (Burkepile et al. 2006).

Although there was a significant reduction in redox potential under the stingray, an indication of lack of oxygen and presence of sulfides, sediment samples near the carcass were also anoxic (Fig. 2). These values were nevertheless within the range reported for vegetated and unvegetated sites in St. Georges Basin (below -100 mV; Murray et al. 2005, McKinnon et al. 2009), suggesting that values sampled outside the carcass are natural for the study area and probably free of effects from the carcass itself. There were no significant differences in the concentrations of sediment
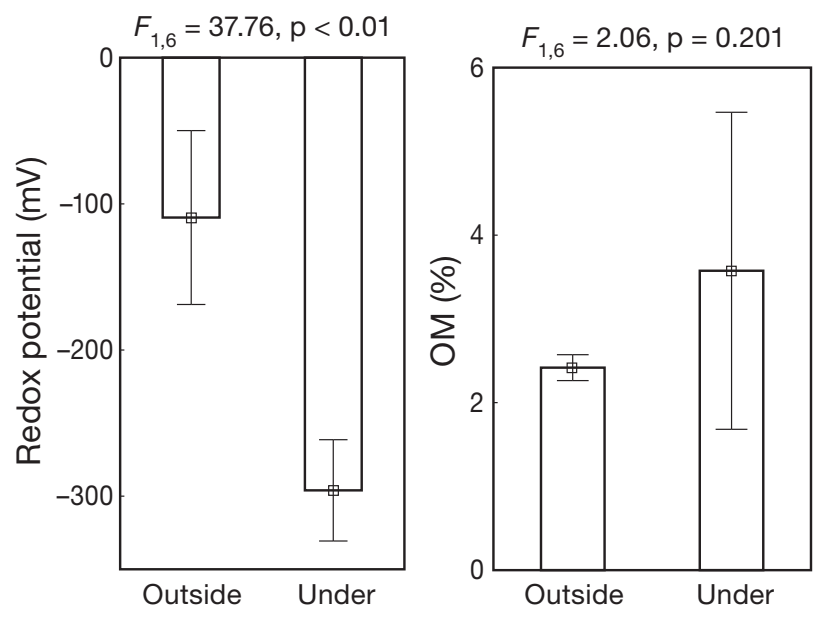

Fig. 2. Redox potentials and organic matter content (OM) from samples taken outside and under the carcass of a stingray. Data are mean \pm SD. ANOVA results are given above each panel 
organic matter between samples taken under and outside the stingray (Fig. 2). This was probably due to the high variability in organic matter values from samples underneath the carcass, since a mosaic of spots with and without remaining flesh was observed. Outside the carcass no flesh was observed.

A total of 12 meiofaunal taxa were encountered (Appendix 1). Meiofaunal abundance and the number of meiofaunal taxa per core were significantly lower underneath the carcass compared to samples outside (Fig. 3a,b). Additionally, meiofaunal composition underneath the carcass was significantly different from samples taken outside the carcass $(\mathrm{R}=0.839$, $\mathrm{p}<0.05$; Fig. 4a). Whereas no meiofaunal taxon occurred exclusively under the carcass, several taxa such as nauplii, turbellarians, oligochaetes, isopods and kinorhynchs were only found in samples outside the carcass (Appendix 1). Other taxa, such as acari and polychaetes, were found only once (as singletons in only 1 sample) under the stingray carcass, but otherwise were restricted to samples outside the carcass. As observed for other aquatic systems (Debenham et al. 2004, Pavlyuk et al. 2009, Premke et al. 2010), the encountered stingray carcass had a negative impact on meiofaunal abundances. Such a negative impact is probably due in part to hypoxia and the presence of toxic sulfides in sediments underneath the carcass, since most of the affected taxa (i.e. taxa that were found in control samples but were not sampled underneath the ray) are known to be more abundant in oxic than in anoxic conditions (Modig \& Ólafsson 1998, Fonseca et al. 2011).

Among the meiofaunal taxa that occurred in sediments underneath the carcass, nematodes dominated all samples, representing 82.2 to $94.7 \%$ of all organisms collected per sample. In total, 29 nematode species were identified (Appendix 1). They showed similar trends to those of total meiofauna (i.e. significantly lower abundance and species richness under the carcass; Fig. 3c,d). Likewise, samples from outside and under the carcass also showed distinct nematode assemblages $(\mathrm{R}=0.59, \mathrm{p}<0.01$; Fig. 4b). In contrast to other meiofaunal taxa, however, there were some nematode species that occurred exclusively under the carcass, such as Adoncholaimus sp. 1, Calomicrolaimus sp. 1 and Microlaimus sp. 1 (SIMPER analysis; Table 1, Appendix 1). Adoncholaimus species are facultative predators that exhibit a variety of feeding strategies (Moens et al. 1999). A. thalassophygas De Man, 1876, for example, can benefit from the fermentation products (acetate) of anoxic habitats (Riemann et al.
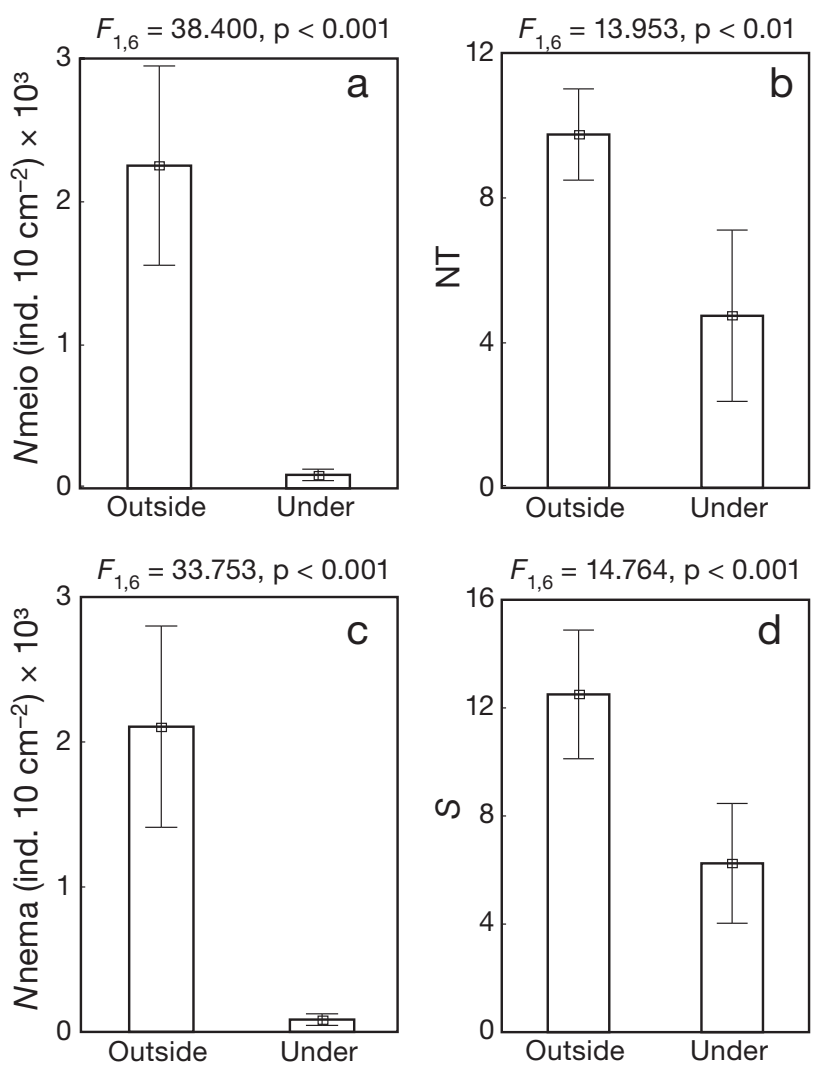

Fig. 3. Meiofaunal and nematode abundances (Nmeio and Nnema, respectively), number of higher taxa (NT) and number of nematode species $(S)$ in samples taken outside and under the carcass of a stingray. Data are mean $\pm \mathrm{SD}$. ANOVA results are given above each panel

1990) and are attracted to patches of intense microbial degradation (Riemann \& Schrage 1988). Studies on other co-familial genera (Oncholaimidae) have also reported members of this family scavenging on dead and moribund macrofauna, as well as being associated with rotted seaweed (Ulva sp.), and occurring in highly polluted areas (Lorenzen et al. 1987, Bett \& Moore 1988, Prein 1988), under seagrasses (Fonseca et al. 2011) and under the noxious seaweed Caulerpa taxifo-

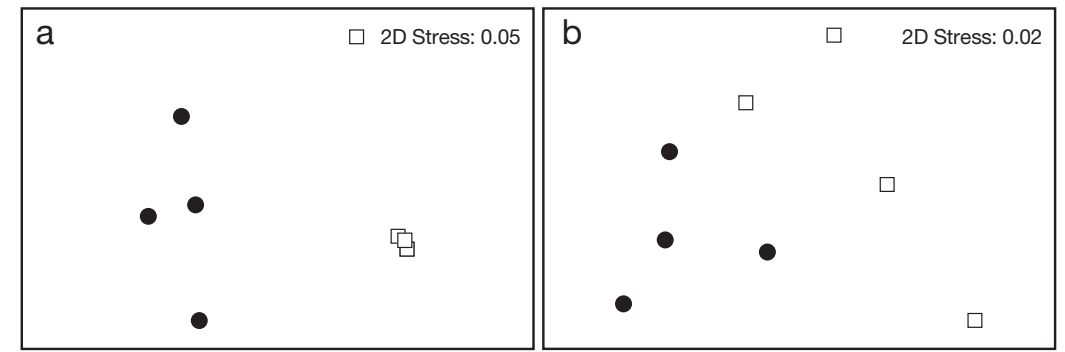

Fig. 4. Ordination plots of multidimensional scaling for (a) the meiofaunal community (presence and absence) and (b) nematode assemblages (standardized data) from samples taken outside (black dots) and under the carcass of a stingray (open squares) 
Table 1. Similarity percentage (SIMPER) results for the nematode assemblage of samples from outside vs. samples from under the carcass. Average dissimilarity $=60.33$. Av. $N$ : average abundance $\left(10 \mathrm{~cm}^{2}\right)$; Cont $\%$ : contribution for the dissimilarity in percentages

\begin{tabular}{|lrrr|}
\hline Species & $\begin{array}{r}\text { Outside } \\
\text { Av. } N\end{array}$ & $\begin{array}{r}\text { Under } \\
\text { Av. } N\end{array}$ & Cont $\%$ \\
\hline Metalinhomoeus sp. 1 & 5.89 & 29.74 & 19.76 \\
Terschellingia sp. 1 & 17.26 & 29.76 & 18.82 \\
Perspiria sp. 1 & 33.50 & 12.39 & 18.64 \\
Gomphionema sp. 1 & 11.54 & 4.72 & 6.79 \\
Daptonema sp. 1 & 7.06 & 10.07 & 6.36 \\
Adoncholaimus sp. 1 & 0.00 & 6.94 & 5.76 \\
Parodontophora sp. 1 & 6.06 & 0.00 & 5.02 \\
Sabatieria sp. 1 & 6.44 & 0.68 & 4.78 \\
Thalassomonhystera sp. 1 & 3.76 & 0.00 & 3.12 \\
Calomicrolaimus sp. 1 & 0.00 & 3.63 & 3.01 \\
\hline
\end{tabular}

lia (F. Gallucci et al. unpubl. data). These observations suggest that oncholaimids tolerate the presence of sulfides, are attracted to putrefied conditions and are able to utilize (parts of) the nutritious mixture of the body remains of dead organisms, bacterial epigrowth, dissolved glucose and the end products of fermentation (Lopez et al. 1979, Riemann et al. 1990, Moens et al. 1999).

The other 2 species restricted to the carcass, Calomicrolaimus sp. 1 and Microlaimus sp. 1 (Appendix 1), are classified as epigrowth feeders, feeding mainly on diatoms and microalgae (the 2A feeding group; Wieser 1953). Calomicrolaimus is one of the dominant genera in anoxic sediments on the Isle of Sylt, Germany (Wetzel et al. 1995), and Microlaimus is considered an opportunistic genus (Lee et al. 2001, Gallucci et al. 2008), which is also associated with naturally hypoxic environments such as sediments colonized by seagrasses (Fonseca et al. 2011) and algal mats (Wetzel et al. 2002). The study area of St. Georges Basin is characterized by large areas of seagrasses $\left(3.170 \mathrm{~km}^{2}\right)$, saltmarshes $\left(0.149 \mathrm{~km}^{2}\right)$ and mangroves $\left(0.276 \mathrm{~km}^{2}\right)$ (Murray et al. 2005), all known to have naturally anoxic sediments. The fact that these 3 species were not encountered in the samples near the carcass suggests they are probably rare in bare sediments and were originally from the surrounding vegetated sites where the sediment is also depleted in oxygen. These species took advantage of the 'favorable' conditions created by carcass decomposition to flourish. Like Adoncholaimus, these genera probably do not feed directly or exclusively on the carcass, but take indirect advantage of the lack of competition in the reduced and toxic environment. Other nematode genera that were favoured under the carcass were Terschellingia sp. 1 and Metalinhomoeus sp. 1 (SIMPER analysis; Table 1). Both genera are well known to contain species that can tolerate anoxic conditions and organic enrichment (Steyaert et al. 2007). Finally, all 5 species mentioned above are long and slender, a morphological adaptation of 'thiobios' nematodes to low oxygen tension and high concentrations of dissolved organic matter (Jensen 1986, 1987, Wetzel et al. 1995).

The present study is limited in the number of experimental units (i.e. carcasses), and we have no information about when the carcass was deposited, hindering full assessment of the effects of carcasses on the meiobenthos. Nonetheless, the results demonstrate that a carcass in estuarine sediments may support a characteristic nematode fauna, distinct from that inhabiting the surrounding sediments, but similar to those of reduced environments. Similar observations have been made for meiofauna of sand beaches (Gerlach 1977), estuarine intertidal areas (Franco et al. 2008) and subtidal areas (Ólafsson 1992). In all these studies it was determined that the nematode species associated with carrion were inhabitants of reduced habitats, which are commonly designated as 'thiobios' (Giere 2009). Such similarity between habitats gives further support to the hypothesis that carrion maintains a specialized set of species across a variety of marine environments (Britton \& Morton 1994), and is of primary importance regarding the distribution of meiobenthos (Ólafsson 1992).

Acknowledgements. G.F. is currently sponsored by Fundação de amparo a pesquisa do estado de São Paulo (FAPESP 2010/05472-0) under Project 2009/14019-0. F.G. is currently sponsored by FAPESP 2010/12232-5 and acknowledges the Australian Government for a postdoctoral Endeavour Research Fellowship during the 2009 calendar year. We acknowledge the critical reading of 3 anonymous referees.

\section{LITERATURE CITED}

Bett BJ, Moore CG (1988) The taxonomy and biology of a new species Pontonema (Nematoda, Oncholaimidae) dominant in organically polluted sublittoral sediments around Scotland, with a review of the genus. J Nat Hist 22:1363-1377

Britton JC, Morton B (1994) Marine carrion and scavengers. Oceanogr Mar Biol Annu Rev 32:369-434

Burkepile DE, Parker JD, Woodson CB, Mills HJ and others (2006) Chemically mediated competition between microbes and animals: microbes as consumers in food webs. Ecology 87:2821-2831

Chaloner DT, Wipfli MS, Caouette JP (2002) Mass loss and macroinvertebrate colonisation of Pacific salmon carcasses in south-eastern Alaskan streams. Freshw Biol 47:263-273

Clarke KR, Gorley RN (2006) Primer v6: user manual/tutorial. PRIMER-E, Plymouth

> Dahlgren TG, Glover AG, Baco A, Smith CR (2004) Fauna of whale falls: systematic and ecology of a new polychaete (Annelida; Chrysopetalidae) from the deep Pacific Ocean. Deep-Sea Res I 51:1873-1887

> Debenham NJ, Lambshead PJD, Ferrero TJ, Smith CR (2004) The impact of whale falls on nematode abundance in the deep sea. Deep-Sea Res I 51:701-706 
Duffy C, Paul L (2003) Dasyatis brevicaudata. In: IUCN 2010. IUCN Red list of threatened species, Version 2010.4. Available at www.iucnredlist.org (accessed on 7 March 2010)

Fenoglio S, Bo TZ, Agosta P, Cucco M (2005) Mass loss and macroinvertebrate colonisation of fish carcasses in riffles and pools of a NW Italian stream. Hydrobiologia 532: $111-122$

Fonseca G, Hutchings P, Gallucci F (2011) Meiobenthic communities of seagrass beds (Zostera capricorni) and unvegetated sediments along the coast of New South Wales, Australia. Estuar Coast Shelf Sci 91:69-77

Franco MA, Steyaert M, Cabral HN, Tenreiro R and others (2008) Impact of discards of beam trawl fishing on the nematode community from the Tagus estuary (Portugal). Mar Pollut Bull 56:1728-1736

Fujikura K, Fujiwara Y, Kawato M (2006) A new species of Osedax (Annelida: Siboglinidae) associated with whale carcasses off Kyushu, Japan. Zoolog Sci 23:733-740

Gallucci F, Fonseca G, Soltwedel T (2008) Effects of megafauna exclusion on nematode assemblages at a deep-sea site. Deep-Sea Res I 55:332-349

Gerlach S (1977) Attraction to decaying organisms as a possible cause for patchy distribution of nematodes in Bermuda beach. Ophelia 16:151-165

Giere O (2009) Meiobenthology: the microscopic motile fauna of aquatic sediments, 2nd edn. Springer-Verlag, Berlin

Glover AG, Källsttröm B, Smith CR, Dahlgren TG (2005) World-wide whale worms? A new species of Osedax from the shallow North Atlantic. Proc Biol Sci 272:2587-2592

> Groenewold S, Fonds M (2000) Effects on benthic scavengers of discard and damaged benthos produced by the beam trawl fishery in the southern North Sea. ICES J Mar Sci 57: 1395-1406

Heip C, Vincx M, Vranken G (1985) The ecology of marine nematodes. Oceanogr Mar Biol Annu Rev 23:399-489

> Hutchings P (1999) Taxonomy of estuarine invertebrates in Australia. Austral Ecol 24:381-394

> Jensen P (1986) Nematode fauna in the sulphide-rich brine seep and adjacent bottoms of the East Flower Garden, NW Gulf of Mexico. IV. Ecological aspects. Mar Biol 92:489-503

> Jensen P (1987) Differences in microhabitats, abundance, biomass and body size between oxybiotic and thiobiotic freeliving marine nematodes. Oecologia 71:564-567

Kaiser MJ, Moore PG (1999) Obligate marine scavengers? Do they exist? J Nat Hist 33:475-481

> Kaiser MJ, Spencer BE (1994) Fish scavenging behaviour in recently trawled areas. Mar Ecol Prog Ser 112:41-49

> King NJ, Bailey DM, Priede IG (2007) Role of scavengers in marine ecosystems. Mar Ecol Prog Ser 350:175-178

> Lee HJ, Vanhove S, Peck LS, Vincx M (2001) Recolonization of meiofauna after catastrophic iceberg scouring in shallow Antarctic sediments. Polar Biol 24:918-925

> Lopez G, Riemann F, Schrage M (1979) Feeding biology of the brackish water oncholaimid nematode Adoncholaimus thalassophygas. Mar Biol 54:311-318

> Lorenzen S, Prein M, Valentin C (1987) Mass aggregations of the free-living marine nematode Pontonema vulgare (Oncholaimidae) in organically polluted fjords. Mar Ecol Prog Ser 37:27-34

McKinnon JG, Gribben PE, Davis AR, Jolley DF, Wright JT (2009) Differences in soft-sediment macrobenthic assemblages invaded by Caulerpa taxifolia compared to uninvaded habitats. Mar Ecol Prog Ser 380:59-71

> Minshall GW, Hitchcock E, Barnes JR (1991) Decomposition of rainbow trout (Oncorhynchus mykiss) carcasses in a forest stream ecosystem inhabited only by non-anadromous fish populations. Can J Fish Aquat Sci 48:191-195
Modig H, Ólafsson E (1998) Responses of Baltic benthic invertebrates to hypoxic events. J Exp Mar Biol Ecol 229: $133-148$

> Moens T, Verbeeck L, Vincx M (1999) Feeding biology of a predatory and a facultatively predatory nematode (Enoploides longispiculosus and Adoncholaimus fuscus). Mar Biol 134:585-593

Murray EJ, Haese RR, Smith CS, Heggie DT (2005) Nutrient cycling in St. Georges Basin, south coast of NSW: report on field survey November 2003. Geoscience Australia, Rec 2005/22

Ólafsson E (1992) Small scale spatial distribution of marine meiobenthos: the effects of decaying macrofauna. Oecologia 90:37-42

> Parmenter RR, Lamarra VA (1991) Nutrient cycling in a freshwater marsh: the decomposition of fish and waterfowl carrion. Limnol Oceanogr 36:976-987

> Pavlyuk ON, Trebukhova YA, Tarasov VG (2009) The impact of implanted whale carcass on nematode communities in shallow water area of Peter the Great Bay (East Sea). Ocean Sci J 44:181-188

Prein M (1988) Evidence for a scavenging lifestyle in the freeliving nematode Pontonema vulgare (Enoplida, Oncholaimidae). Kieler Meeresforsch 6:389-394

Premke K, Fischer P, Hempel M, Rothhaupt KO (2010) Ecological studies on the decomposition rate of fish carcasses by benthic organisms in the littoral zone of Lake Constance, Germany. Ann Limnol-Int J Limnol 46:157-168

> Ramsay K, Kaiser MJ, Moore PG, Hughes RN (1997) Consumption of fisheries discards by benthic scavengers: utilization of energy subsidies in different marine habitats. J Anim Ecol 86:884-896

Riemann F, Schrage M (1988) Carbon dioxide as an attractant for the free-living marine nematode Adoncholaimus thalassophygas. Mar Biol 98:81-85

Riemann F, Ernst W, Ernst R (1990) Acetate uptake from ambient water by the free-living marine nematode Adoncholaimus thalassophygas. Mar Biol 104:453-457

Smith CR, Baco AR (2003) Ecology of whale falls at the deepsea floor. Oceanogr Mar Biol Annu Rev 41:311-354

Smith CR, Baco AR, Glover GA (2002) Fauna succession on replicate deep-sea whale falls: time scales and vent-seep on affinities. Cah Biol Mar 43:293-297

Stevens JD (2008) Dasyatis thetidis. In: IUCN 2010. IUCN Red list of threatened species, Version 2010.4. Available at: www.iucnredlist.org (accessed on 7 March 2010)

> Steyaert M, Moodley L, Nadong T, Moens T, Soetaert K, Vincx M (2007) Responses of intertidal nematodes to shortterm anoxic events. J Exp Mar Biol Ecol 345:175-184

Tang KW, Hutalle KML, Grossart HP (2006) Microbial abundance, composition and enzymatic activity during decomposition of copepod carcasses. Aquat Microb Ecol 45:219-227

Warwick RM, Platt HM, Somerfield PJ (1998) Free-living marine nematodes, Part III. British monhysterids. In: Barnes RSK, Crothers J (eds) Synopses of the British fauna. New Series 53. Field Studies Council, Shrewsbury

> Wetzel MA, Jensen P, Giere O (1995) Oxygen/sulfide regime and nematode fauna associated with Arenicola marina burrows: new insights in the thiobios case. Mar Biol 124: 301-312

> Wetzel MA, Weber A, Giere O (2002) Re-colonization of anoxic/sulfidic sediments by marine nematodes after experimental removal of macroalgal cover. Mar Biol 141: 679-689

Wieser W (1953) Die Beziehung zwischen Mundhöhlengestalt, Ernährungsweise und Vorkommen bei freilebenden marinen Nematoden. Arkiv Zool 4:439-484 
Appendix 1. Absolute abundance of higher meiofaunal taxa (ind. $10 \mathrm{~cm}^{-2}$ ) and relative abundance of nematode species in each replicate (A to D) encountered outside and under the carcass of a stingray in St. Georges Basin, NSW, Australia

\begin{tabular}{|c|c|c|c|c|c|c|c|c|}
\hline & \multicolumn{4}{|c|}{ Outside the carcass } & \multicolumn{4}{|c|}{ Under the carcass } \\
\hline & A & B & $\mathrm{C}$ & $\mathrm{D}$ & A & B & $\mathrm{C}$ & $\mathrm{D}$ \\
\hline \multicolumn{9}{|l|}{ Higher meiofaunal taxa } \\
\hline Nematodes & 7272 & 8183 & 7605 & 3391 & 339 & 393 & 110 & 232 \\
\hline Copepods & 226 & 430 & 308 & 327 & 6 & 22 & 16 & 19 \\
\hline Nauplii & 82 & 25 & 66 & 72 & 0 & 0 & 0 & 0 \\
\hline Ostracods & 31 & 6 & 6 & 25 & 6 & 3 & 3 & 3 \\
\hline Kinorhynchs & 19 & 19 & 28 & 13 & 0 & 0 & 0 & 0 \\
\hline Polychaete larvae & 13 & 0 & 31 & 13 & 0 & 0 & 0 & 3 \\
\hline Polychaetes & 9 & 9 & 9 & 0 & 3 & 0 & 0 & 0 \\
\hline Isopods & 9 & 3 & 0 & 3 & 0 & 0 & 0 & 13 \\
\hline Turbellarians & 9 & 0 & 9 & 0 & 0 & 0 & 0 & 0 \\
\hline Oligochaetes & 9 & 3 & 0 & 6 & 0 & 0 & 0 & 0 \\
\hline Acari & 6 & 0 & 6 & 3 & 0 & 0 & 0 & 3 \\
\hline Gastropods & 0 & 0 & 3 & 3 & 3 & 0 & 0 & 6 \\
\hline \multicolumn{9}{|l|}{ Nematode species } \\
\hline Perspiria sp. 1 & 19.6 & 32.7 & 53.8 & 15.9 & 3.6 & 8.7 & 8.0 & 15.5 \\
\hline Terschellingia sp. 1 & 15.0 & 35.4 & 7.1 & 5.3 & 47.0 & 20.2 & 0.0 & 27.6 \\
\hline Metalinhomoeus sp. 1 & 13.8 & 5.0 & 2.0 & 3.8 & 15.7 & 35.6 & 32.0 & 12.1 \\
\hline Daptonema spp. & 6.7 & 1.5 & 8.7 & 18.9 & 10.8 & 12.5 & 12.0 & 1.7 \\
\hline Gomphionema sp. 1 & 14.2 & 3.8 & 6.7 & 27.3 & 7.2 & 4.8 & 0.0 & 3.4 \\
\hline Sabatieria sp. 1 & 14.2 & 3.1 & 4.7 & 5.3 & 2.4 & 1.0 & 4.0 & 1.7 \\
\hline Parodontophora sp. 1 & 6.7 & 7.7 & 3.2 & 7.6 & 0.0 & 0.0 & 0.0 & 1.7 \\
\hline Adoncholaimus sp. 1 & 0.0 & 0.0 & 0.0 & 0.0 & 0.0 & 0.0 & 20.0 & 0.0 \\
\hline Thalassomonhystera sp. 1 & 2.1 & 1.2 & 4.0 & 6.1 & 0.0 & 1.0 & 0.0 & 0.0 \\
\hline Theristus spp. & 1.7 & 2.3 & 1.2 & 0.8 & 2.4 & 0.0 & 4.0 & 0.0 \\
\hline Pseudochomadora sp. 1 & 0.4 & 1.5 & 0.4 & 3.8 & 0.0 & 0.0 & 4.0 & 1.7 \\
\hline Calomicrolaimus sp. 1 & 0.0 & 0.0 & 0.0 & 0.0 & 2.4 & 5.8 & 0.0 & 3.4 \\
\hline Ptycholaimellus sp. 1 & 1.3 & 0.4 & 2.4 & 3.0 & 0.0 & 2.9 & 0.0 & 0.0 \\
\hline Cobbia sp. 1 & 2.1 & 0.4 & 2.4 & 0.8 & 0.0 & 0.0 & 0.0 & 1.7 \\
\hline Paracyatholaimus sp. 1 & 2.1 & 0.0 & 1.6 & 0.0 & 0.0 & 0.0 & 0.0 & 1.7 \\
\hline Spirinia sp. 1 & 0.0 & 0.0 & 0.4 & 0.0 & 0.0 & 2.9 & 0.0 & 1.7 \\
\hline Prochromadorella sp. 1 & 0.0 & 0.0 & 0.0 & 0.0 & 0.0 & 1.0 & 4.0 & 0.0 \\
\hline Chromadora sp. 1 & 0.0 & 0.4 & 0.0 & 0.0 & 0.0 & 0.0 & 4.0 & 0.0 \\
\hline Dorylaimidae sp. 1 & 0.0 & 0.0 & 0.0 & 0.0 & 0.0 & 0.0 & 4.0 & 0.0 \\
\hline Eurystomina sp. 1 & 0.0 & 0.0 & 0.0 & 0.0 & 0.0 & 0.0 & 4.0 & 0.0 \\
\hline Microlaimus sp. 1 & 0.0 & 0.0 & 0.0 & 0.0 & 0.0 & 1.9 & 0.0 & 0.0 \\
\hline Linhomoeus sp. 1 & 0.0 & 0.0 & 0.4 & 0.0 & 1.2 & 0.0 & 0.0 & 0.0 \\
\hline Comesa sp. 1 & 0.0 & 0.0 & 0.0 & 0.0 & 1.2 & 0.0 & 0.0 & 0.0 \\
\hline Megadesmolaimus sp. 1 & 0.0 & 0.0 & 0.0 & 0.0 & 1.2 & 0.0 & 0.0 & 0.0 \\
\hline Paralinhomoeus sp. 1 & 0.0 & 0.0 & 0.0 & 0.0 & 1.2 & 0.0 & 0.0 & 0.0 \\
\hline Paracomesoma sp. 1 & 0.4 & 0.4 & 0.4 & 0.0 & 0.0 & 0.0 & 0.0 & 0.0 \\
\hline Chromadorina sp. 1 & 0.0 & 0.0 & 0.0 & 0.0 & 0.0 & 1.0 & 0.0 & 0.0 \\
\hline Desmolaimus sp. 1 & 0.0 & 0.0 & 0.0 & 0.0 & 0.0 & 1.0 & 0.0 & 0.0 \\
\hline Sphaerolaimus sp. 1 & 0.0 & 0.4 & 0.4 & 0.0 & 0.0 & 0.0 & 0.0 & 0.0 \\
\hline
\end{tabular}

Editorial responsibility: Hans Heinrich Janssen, Oldendorf/Luhe, Germany
Submitted: February 2, 2011; Accepted: April 18, 2011 Proofs received from author(s): June 22, 2011 